\title{
Lead contamination: Chronic and acute behavioral effects in the albino rat
}

\author{
MARTIN M. SHAPIRO, J. M. TRITSCHLER \\ and RONALD A. ULM \\ Emory University, Atlanta, Ga. 30322
}

\begin{abstract}
Rats trained on an operant discrimination were subjected daily to a low level of lead contamination. Chronic contamination increased the variability of the discrimination behavior. Increased contamination produced an acute shift in the distribution of interresponse times.
\end{abstract}

Environmental contamination has received increasing interest and concern. The common assumption has been that practical tolerance limits can be established by studying the biological effects of contamination. However, low levels of some contaminants produce generally nonspecific symptoms which are not well correlated with the concentrations of the contaminant retained in the body tissues. Lead contamination, for example, may produce headaches, anorexia, increased irritability, vomiting, pallor, constipation, anemia, or abdominal pain within a wide range of lead levels in the blood. Because these symptoms are generally unalarming, early diagnosis of lead contamination is the exceptional case. Plumbism is often unsuspected until manifestations of severe neurological damage appear (Engel, Hammer, Horton, Lane, \& Plumlee, 1971). The purpose of this paper is to investigate some possible effects of very low levels of lead contamination (Schroeder, Balassa, \& Vincton, 1965) upon behavior. An attempt is made to measure the subtle variability in behavior that might be expected to accompany or even precede the generally nonspecific clinical symptoms.

\section{METHOD}

Fourteen 90-day-old male albino rats were deprived of water and trained in an experimental cubicle which contained a lever, cue lights, and a dipper that delivered $0.1 \mathrm{ml}$ of a $0.004 \mathrm{M}$ sodium saccharin solution. The rats were trained to drink from the dipper, and the leverpress response was shaped by successive approximations. The leverpress reinforcement was reduced to a 30 -sec variable-interval schedule; that is, saccharin reinforcement was presented following the first leverpress that occurred after a variable interval had elapsed, the mean length of the interval being $30 \mathrm{sec}$. Discrimination training consisted of a $10-\mathrm{min}$ interval, during which reinforcements were available on the variable-interval schedule, alternating with a 10 -min extinction interval during which no reinforcements were available. Each daily 60 -min session ran through three full cycles, beginning with a variable-interval schedule of reinforcement and ending with extinction. The cue lights were illuminated during the variable-interval schedule in one-half of the cubicles and were illuminated during extinction in the other cubicles. Each leverpress advanced a tape punch, which recorded the time at which the press occurred to the nearest $0.5 \mathrm{sec}$. Recording was begun on the seventh day of discrimination training. Treatment was begun following the end of the ninth session of discrimination training. For the seven rats in the control group. an IP injection of normal saline was administered $(0.25 \mathrm{ml} / 100 \mathrm{~g}$ body weight) following each session. For the seven rats in the experimental group, an IP injection of lead acetate dissolved in normal saline (64 micrograms $/ \mathrm{ml}$ ) was administered $(0.25 \mathrm{ml} / 100 \mathrm{~g}$ body weight) following each session. The daily experimental dose was, therefore, 16 micrograms $/ 100 \mathrm{~g}$ body weight. This treatment was continued for 36 days, after which the treatment time and dosage level were altered. Four additional daily sessions were run with the IP injections administered 30 min prior to each session, instead of at the end of the previous session, and the dosage increased to 384 micrograms of lead acetate per milliliter of normal saline ( 96 micrograms/100 $\mathrm{g}$ body weight).

\section{RESULTS AND DISCUSSION}

The experimental group showed no general debilitation in their behavior; their absolute rate of responding was unchanged throughout the experiment. A discrimination ratio was computed for each of the three pairs of 10-min reinforcement and extinction periods during each session. This ratio was the number of leverpresses during variable-interval reinforcement divided by the sum of the number of leverpresses during variable-interval reinforcement plus extinction. A perfect performance is a ratio of 1 ; a chance performance is a ratio of 0.5 . The mean of these three discrimination ratios was used as the session score for each $\mathrm{S}$. The results for the individual animals of the two groups on the 4 days prior to and following the increased contamination are shown in Fig. 1. An inspection of the discrimination ratios during the 4 days prior to the increase in contamination reveals that the experimental group was more variable than the control group. The estimate of the within-S variance between days was calculated and the $F$ ratio between groups was statistically significant $[F(21,21)=4.75 ; p<.001]$. The mean estimate of between-S variance within each day was calculated, and this $F$ ratio between groups was also statistically significant $[F(6,6)=9.71 ; p<.01]$. Therefore, a chronic effect of the 36 days of 16 micrograms $/ 100 \mathrm{~g}$ of body weight injection was a statistically significant increase in variability. Similar analyses of variance estimates were conducted for the 3 baseline days prior to the initiation of the treatment. There were no significant baseline differences between the two groups.

Consider the discrimination ratios for the 4 days after the acute increase in contamination (Fig. 1). The behavior of the control animals remained within its 

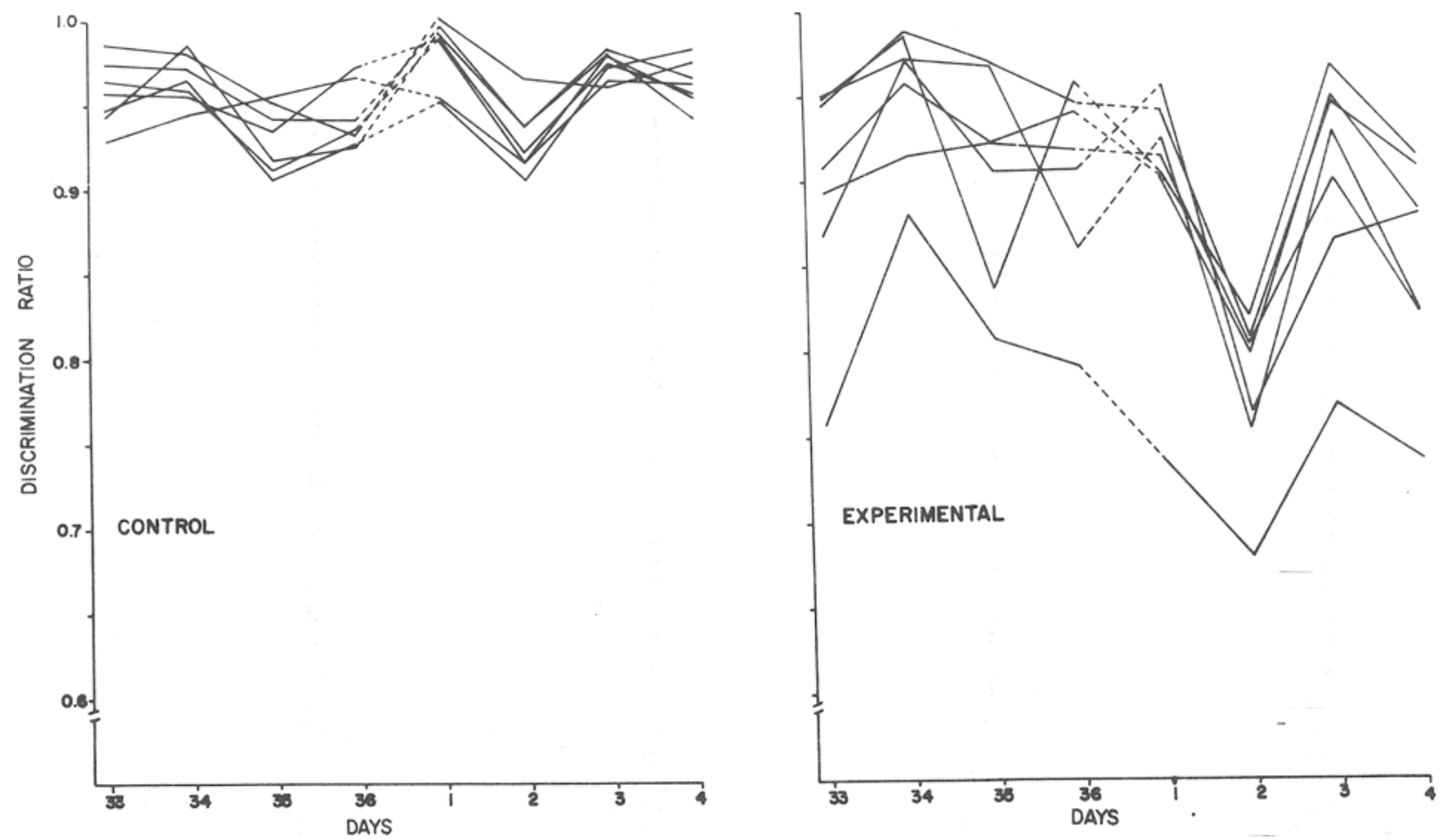

Fig. 1. Discrimination ratios for the individual Ss in the control and experimental groups for the 4 days before and after the alteration in contamination.

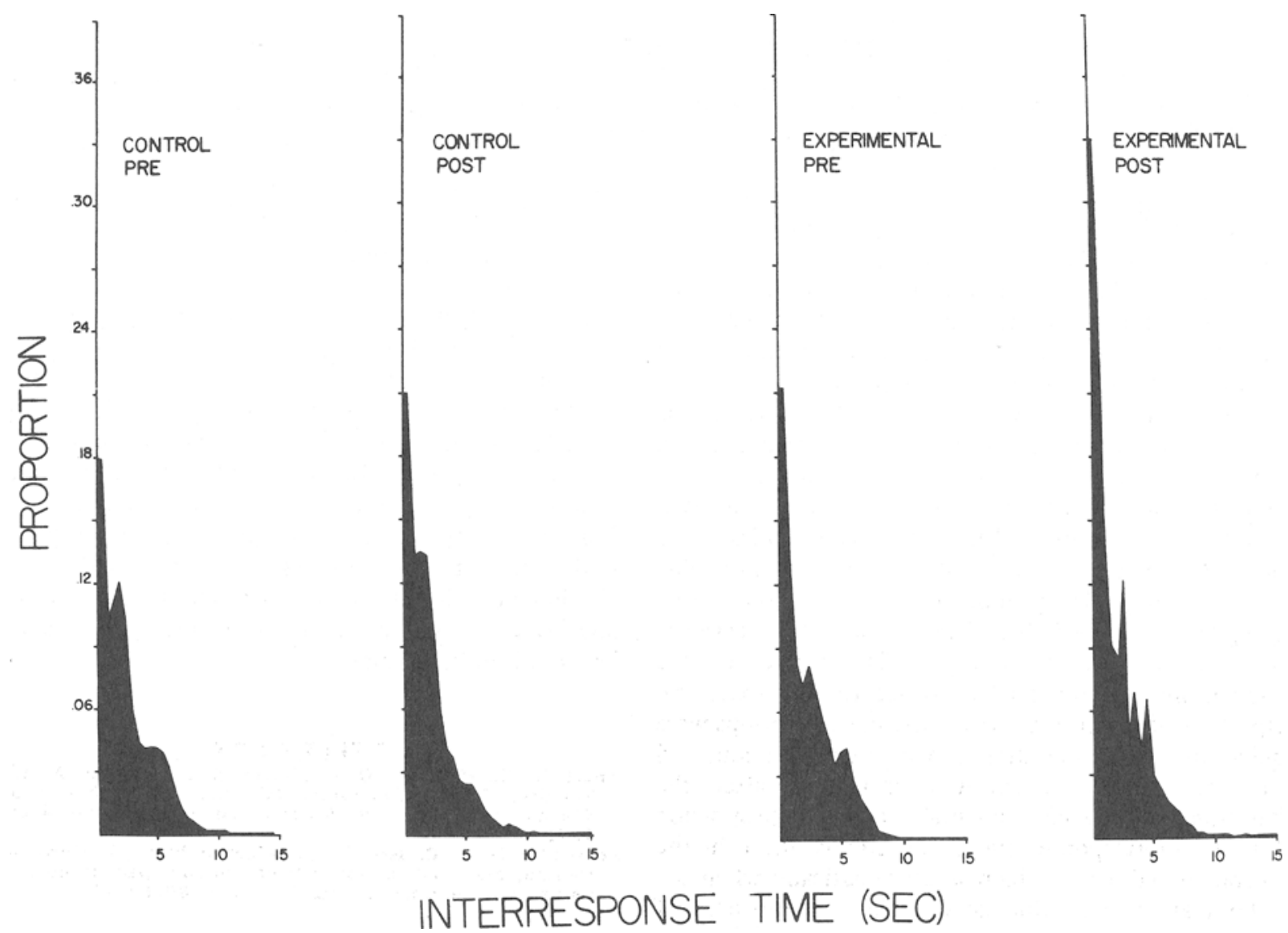

Fig. 2. Mean proportion of interresponse times, in $\mathbf{0 . 5}$-sec intervals, for the control and experimental groups during the 4 days before and after the alteration in contamination. The graphs are truncated at $15 \mathrm{sec}$. 

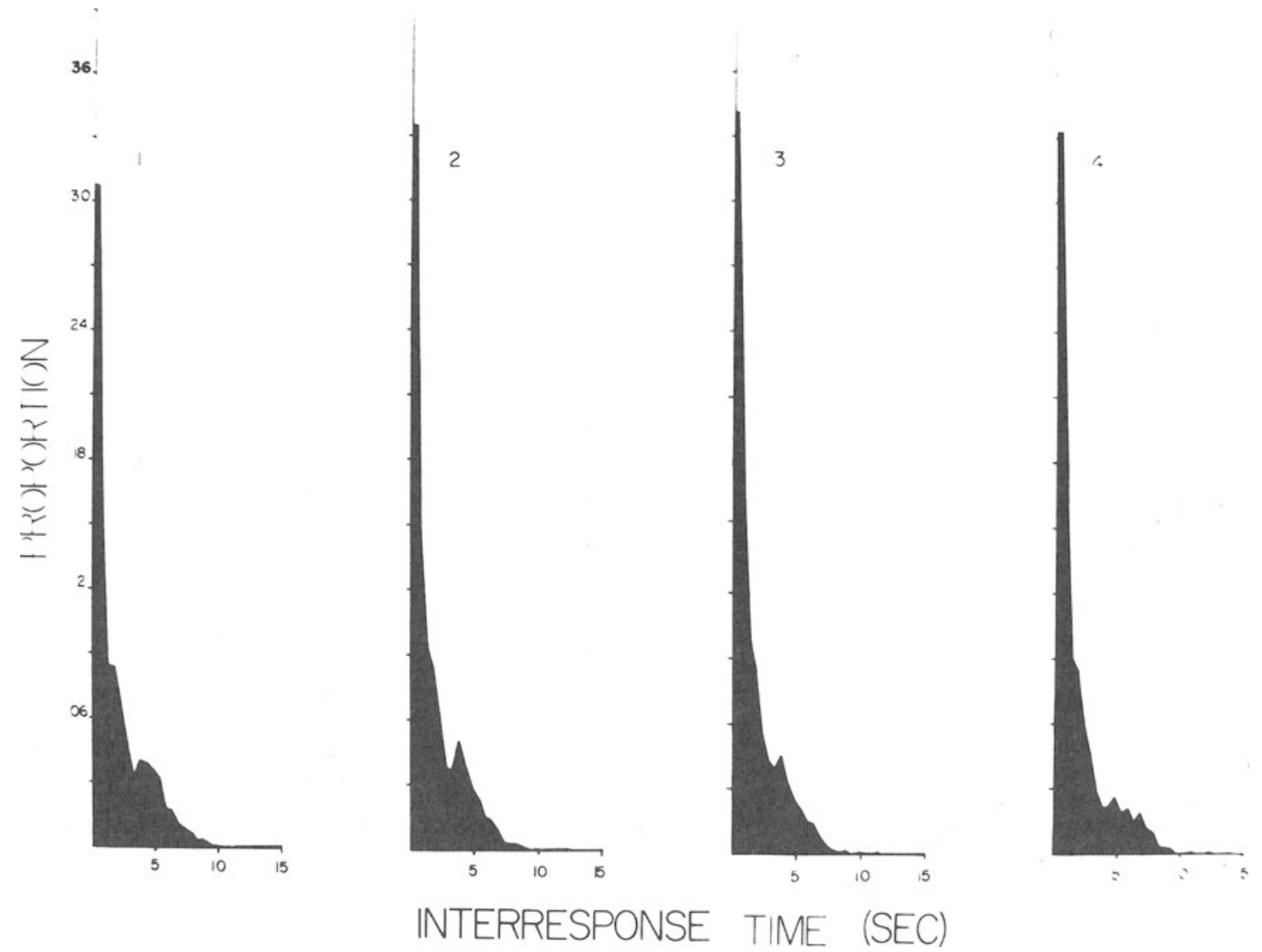

Fig. 3. Mean proportion of interresponse times for the experimental group, in 0.5 -sec intervals, during each of the 4 days after the alteration in contamination. The graphs are truncated at $15 \mathrm{sec}$.

previous range, while the discrimination ratios dropped sharply for all of the experimental animals on the second day. The delay of the effect until the second day was perplexing. An analysis of body weight for each animal revealed stability over days and excluded any relationship to water motivation. A computer analysis of interresponse times was much more profitable.

Interresponse time was defined as the real time $( \pm 0.5 \mathrm{sec})$ between successive pairs of responses. A frequency distribution of interresponse times during the three reinforcement periods was tabulated for each animal each session. These frequency tables were converted to proportion tables to permit averaging across Ss or days. The proportions of interresponse times during the 4-day periods before and after the treatment alteration are shown in Fig. 2. The graphs of the distributions are truncated at $15 \mathrm{sec}$ to save space. An inspection of the curves reveals that the two groups were equivalent before the alteration in contamination, and that the control group was unchanged after the alteration. For the experimental group, the proportion of short interresponse times, particularly those in the interval of $0.0-0.5 \mathrm{sec}$, increased dramatically when the contamination was increased. The proportions of interresponse times for each of the 4 days after the alteration are shown in Fig. 3. It is apparent that the proportion of short interresponse times increased on the first day and remained at the elevated level on all 4 days. Chi-square tests of goodness-of-fit were significant for each individual $S$ of the experimental group. All experimental Ss displayed a consistent discrete shift in their distributions of interresponse times.

The results of this investigation support the feasibility of studying the behavioral effects of low levels of contamination and raise the possibility that behavioral measures may be sensitive indicators in some instances. This possibility is especially appealing with respect to lead contamination because of the difficulty of obtaining consistent dose-response relationships between low levels of exposure and, for example, the resultant levels of lead in the blood.

\section{REFERENCES}

Engel, R. E Hammer, D. I., Hortin, R. J. M., Lane, N. M., \& Plumlee, L. A. Environmental lead and public health. Washington, D.C: U.S. Environmental Protection Agency, 1971.

Schroeder, H. A., Balassa, J. J., \& Vincton, W. H., Jr. Chromium, cadium, and lead in rats: Effects on life span, tumors, and tissue levels. Journal of Nutrition, 1965, 86, 51-66.

(Received for publication May 29, 1972.) 